Research Article

\title{
Seismic Performance of an Efficient Scissor-Jack-Damper Configuration
}

\author{
Lihua Zhu $\mathbb{D}^{1,2}$ Pengyu Guo $\mathbb{D}^{1},{ }^{1}$ Chenglong Hua, ${ }^{1}$ and Shiyu Shan ${ }^{1}$ \\ ${ }^{1}$ School of Civil Engineering, Xi'an University of Architecture \& Technology, Xi'an 710055, China \\ ${ }^{2}$ Key Lab of Structural Engineering and Earthquake Resistance, Ministry of Education (XAUAT), Xi'an 710055, China \\ Correspondence should be addressed to Lihua Zhu; zhulihuaxa@163.com
}

Received 8 September 2019; Revised 28 November 2019; Accepted 4 December 2019; Published 16 March 2020

Academic Editor: Roger Serra

Copyright (c) 2020 Lihua Zhu et al. This is an open access article distributed under the Creative Commons Attribution License, which permits unrestricted use, distribution, and reproduction in any medium, provided the original work is properly cited.

Energy-dissipating or damping systems have been widely used in new and retrofitted structures for reducing earthquake damage to structural frames. Most damping devices were installed using diagonal or chevronbrace configurations, until the development of toggle-brace and scissor-jack configurations. This paper presents a modified scissor-jack-damper configuration with substantially improved efficiency. The mechanical behavior of the efficient scissor-jack-damper configuration is analyzed theoretically, and a formula for the displacement magnification factor of the configuration is proposed. A steel-frame specimen installed with the efficient scissor-jack-damper configuration was tested to verify the accuracy of the formula. The seismic responses of an uncontrolled steel-frame structure and of two controlled structures, installed with a diagonal brace and efficient scissor-jack-damper configurations, were analyzed using SAP2000. The high efficiency of the proposed scissor-jack-damper configuration is thus verified for practical engineering situations.

\section{Introduction}

In recent years, damping devices or energy dissipation systems have been widely used to dissipate the large amounts of earthquake-induced energy that would be absorbed by a structural framing system via inelastic deformations [1, 2]. The underlying principle of all damping devices is to reduce or eliminate damage to structural frames. These systems exhibit either hysteretic or viscoelastic behavior [3-5].

Various types of damping devices have been used in new and retrofitted constructions to reduce wind- and earthquake-induced vibrations. The diagonal-brace and chevronbrace configurations were first used to transmit forces from the energy-dissipating system to the structural frame. Subsequently, the toggle-brace configuration was developed, suitable for applications involving the reduction of wind response and the mitigation of seismic-hazard in stiff structures $[6,7]$. The scissor-jack-damper energy dissipation system, a variant of the toggle-brace-damper seismic-energy-dissipating system, was developed to achieve displacement magnification and to meet architectural requirements, such as providing an open space and an unobstructed view [8-10]. Seismic design approaches of the structure with various viscous damper installation configurations were proposed in some literature studies [11, 12].

With a view to improving mechanical performance, this study developed an efficient scissor-jack-damper configuration. A theory regarding the configuration is presented, and a dynamic-loading test on a steel-frame specimen was conducted to verify the theory. Moreover, the seismic response of a structure with the efficient scissor-jack-damper configuration was numerically analyzed using SAP2000 and compared with the responses of an uncontrolled structure and of a structure with a diagonal-brace configuration.

\section{Theoretical Analysis}

2.1. Efficient Scissor-Jack-Damper Configuration. A scissorjack damping system has the advantage of forming an open space in the bay of a structural frame, owing to its compactness and near-vertical installation. However, a concentrated load is observed to act on the beam when the 
structural frame is subjected to a horizontal action. This path of force transmission is suboptimal for seismic loads. In addition, the energy-dissipation efficiency of the scissorjack-damper system is insufficient for some stiffer structures that require greater magnification factors. With this motivation, an efficient scissor-jack-damper configuration was developed. This modified scissor-jack-damper system has a significantly higher efficiency to suit stiffer structures. As illustrated in Figure 1, the configuration is connected to the column-beam joint instead of the beam, which facilitates load transfer.

\subsection{Theoretical Analysis on the Efficient Scissor-Jack-Damper} System. Similar to other damper installation configurations (including the diagonal-brace, chevron-brace, toggle-brace, and scissor-jack), the displacement magnification factor $f$ of the efficient scissor-jack-damper configuration is defined as the ratio of the damper relative displacement $u_{\mathrm{D}}$ to the interstory drift $u$ where the devices are installed:

$$
f=\frac{u_{\mathrm{D}}}{u} \text {. }
$$

Similarly, the damping force $F_{\mathrm{D}}$, directed along the damper axis, is related to the lateral force $F$ acting on the frame as

$$
F=f \cdot F_{\mathrm{D}}
$$

Consider a single-story frame structure with an efficient scissor-jack-damper configuration, an effective weight $W$, and a fundamental period of vibration $T$ under elastic conditions. The force $F_{\mathrm{D}}$ for the fitted linear viscous damper is given by

$$
F_{\mathrm{D}}=C_{0} \cdot \dot{u}_{\mathrm{D}}
$$

where $C_{0}$ is the damping coefficient and $\dot{u}_{\mathrm{D}}$ is the relative velocity between the ends of the damper along its axis. It follows that the damping ratio of the frame structure can be written as [6]

$$
\beta=\frac{C_{0} \cdot f^{2} \cdot g \cdot T}{4 \cdot \pi \cdot W},
$$

where $g$ is the acceleration due to gravity. Equation (4) implies that a device with a greater magnification factor is more effective at enhancing the damping ratio.

For a multistory frame structure with an efficient scissorjack-damper configuration, the damping ratio can be expressed as [13]

$$
\beta_{k}=\frac{T_{k} \sum_{j} C_{j} f_{j}^{2} \phi_{r j}^{2} g}{4 \pi \sum_{i} W_{i} \phi_{i}^{2}}
$$

where $T_{k}$ denotes the period of vibration of the $k$ th mode, $C_{j}$ is the damping coefficient of the damping device installed in story $j, f_{j}$ is the magnification factor of the damping system, $\phi_{r j}$ is the $k$ th mode relative displacement in story $j, W_{i}$ is the reactive weight of floor level $i$, and $\phi_{i}$ is the $k$ th mode displacement at floor $i$. It is straightforward to show that, for a single-story structure, $\phi_{r j}=\phi_{i}=1$ and $i=j=1$ so that equation (5) simplifies to equation (4).

The above equations reveal that the magnification factor is a key parameter of the efficient scissor-jack-damper configuration. Indeed, the magnification factor is an important factor for evaluating the efficiency of damping systems, and the damping ratio is also related to the magnification factor.

The motions of the efficient scissor-jack-damper configuration are illustrated in Figure 2. It should be noted that any deformation in the frame and any reduction in height due to the rotation of the columns are neglected in the deformed configuration in Figure 2, which means that only rigid body motion is considered $[14,15]$.

The magnification factor of the efficient scissor-jackdamper configuration can be expressed as [8]

$$
f=\frac{\cos \psi}{\tan \theta} \text {. }
$$

The relationship between the magnification factor $f$ and angles $\theta$ and $\psi$, as specified in equation (6), is illustrated in Figure 3.

For an efficient scissor-jack-damper configuration with $\theta=9.5^{\circ}$ and $\psi=40^{\circ}$, equation (6) predicts $f=4.58$. If a viscous damper is installed in the conventional scissor-jackdamper configuration, because the scissor jack is connected to the beam, $\psi$ can increase to as much as $70^{\circ}$. Then, $f$ decreases to 2.04 , which is considerably less than for the efficient scissor-jack-damper configuration.

Compared with the toggle-brace and scissor-jack configurations, a displacement magnification factor in the range 3.0 to 5.0 is practically achievable by the efficient scissorjack-damper configuration (i.e., where the damper displacement is between 3.0 and 5.0 times the interstory drift). Fluid viscous damper systems often require highly detailed designs for dealing with small drifts, which entail substantial increases in size and cost. The efficient scissor-jack configuration then becomes beneficial and significantly economical in cases involving small interstory drifts in some stiff structures [16, 17].

\section{Experiment on the Efficient Scissor-Jack- Damper System}

3.1. Test on the Fluid Viscous Damper. To verify the accuracy of equation (5), a single-story steel-frame specimen was constructed with the proposed scissor-jack configuration and tested experimentally. A fluid viscous damper was utilized for the testing, parameterized by $C_{0}=43.6 \mathrm{~N} \cdot \mathrm{s} / \mathrm{mm}$ for a velocity up to $500 \mathrm{~mm} / \mathrm{s}$. The damper had a stroke of $\pm 50 \mathrm{~mm}$. The fluid viscous damper was first tested under a harmonic load [18], as shown in Figure 4. The displacement amplitudes of the loadings were 2, 4 , and $6 \mathrm{~mm}$, and loading frequencies were $1,2,3$, and $4 \mathrm{~Hz}$, giving a total of 12 loading conditions. A selection of test results is shown in Figure 5. The damping force-displacement hysteresis curves are very full, indicating that the damper has a good dissipation capacity. Moreover, for small displacements and frequencies, the damping force-displacement 


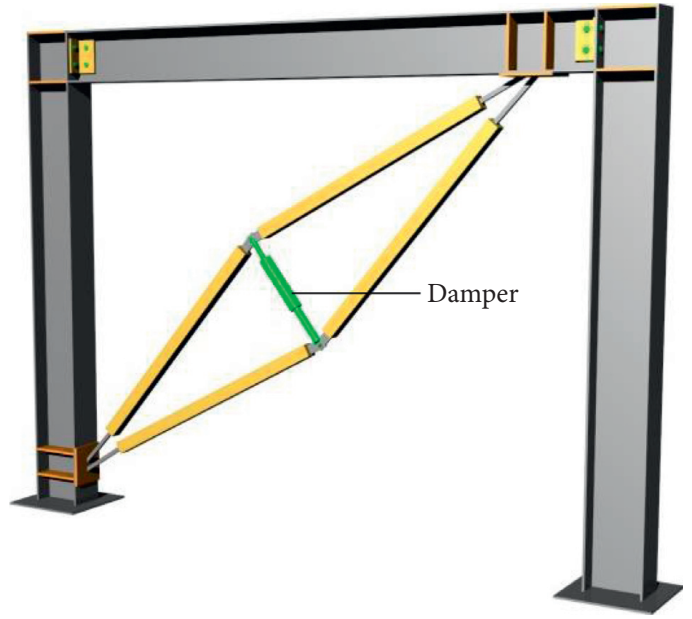

FigURe 1: Efficient scissor-jack-damper configuration.

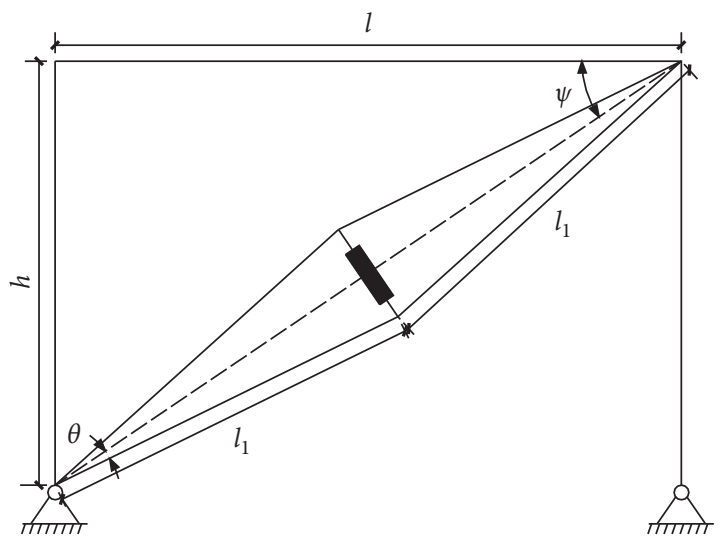

(a)

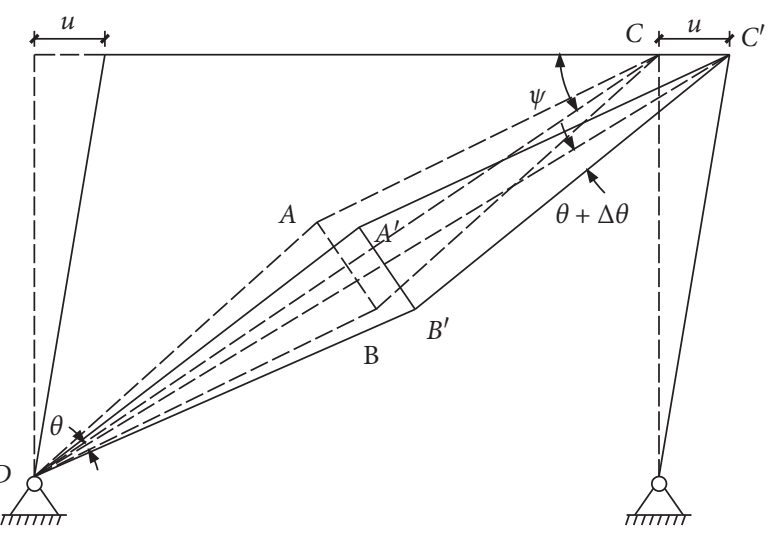

(b)

Figure 2: Analysis of the efficient scissor-jack-damper configuration motions.

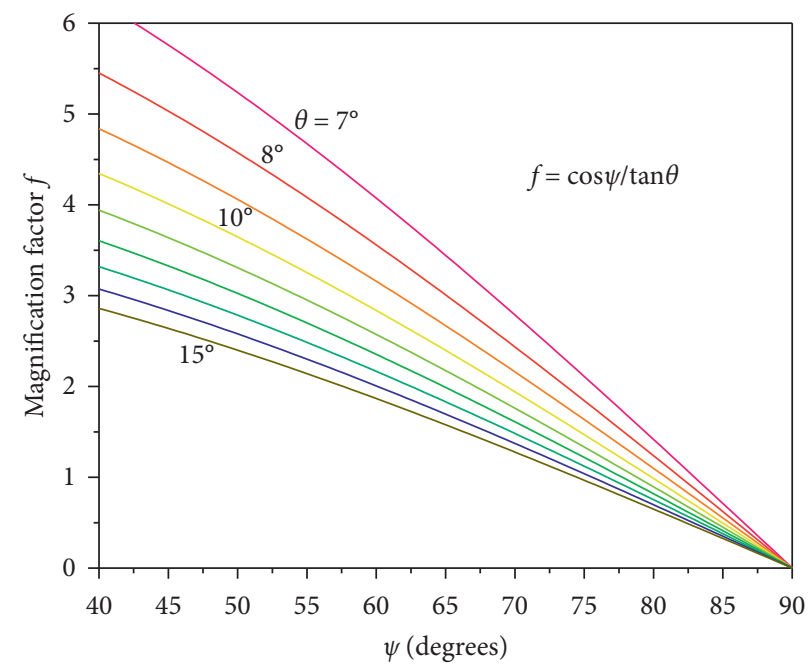

FIgURE 3: Dependence of the magnification factor on the efficient scissor-jack geometry.

hysteresis curve of the damper is nearly rectangular, in accordance with the hysteresis curve expected of a typical nonlinear viscous damper.
3.2. Experimental Program. The specimen geometry shown in Figure 6 was a half-scale steel-frame structure model. The frame spanned $2.5 \mathrm{~m}$ in length and $1.9 \mathrm{~m}$ in height. 


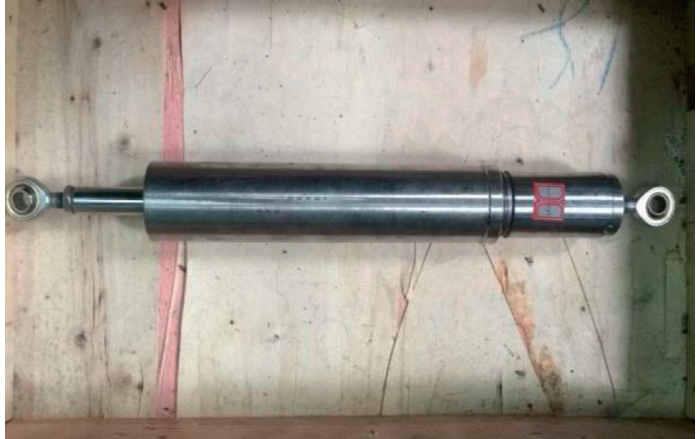

(a)

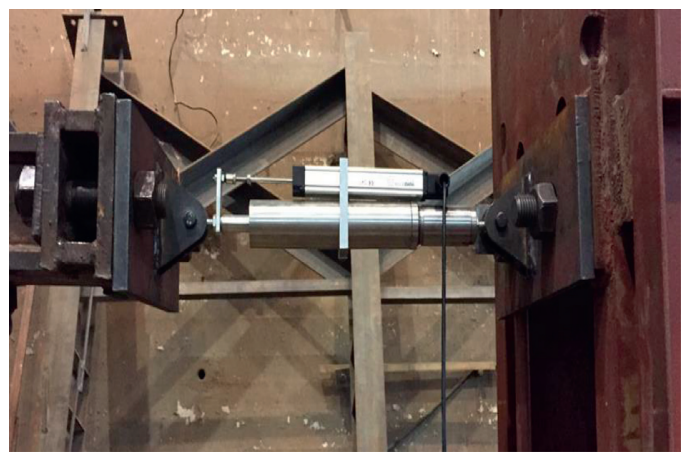

(b)

Figure 4: Testing a fluid viscous damper. (a) Fluid viscous damper. (b) Loading on a fluid viscous damper.

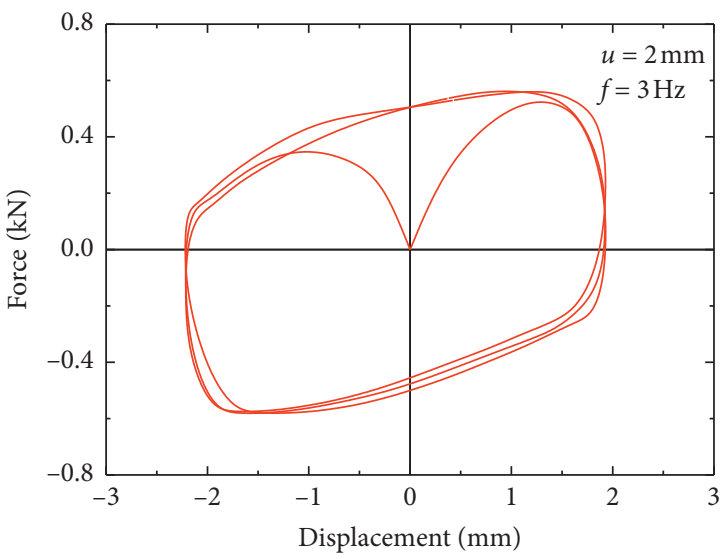

(a)

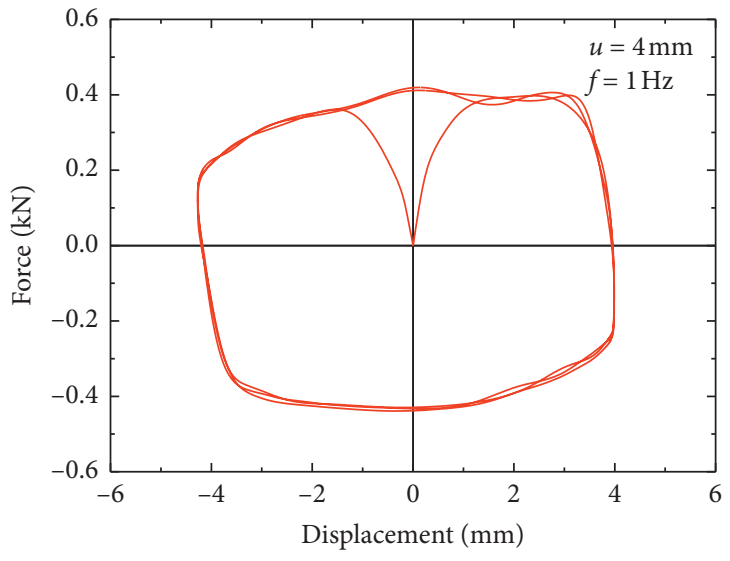

(c)

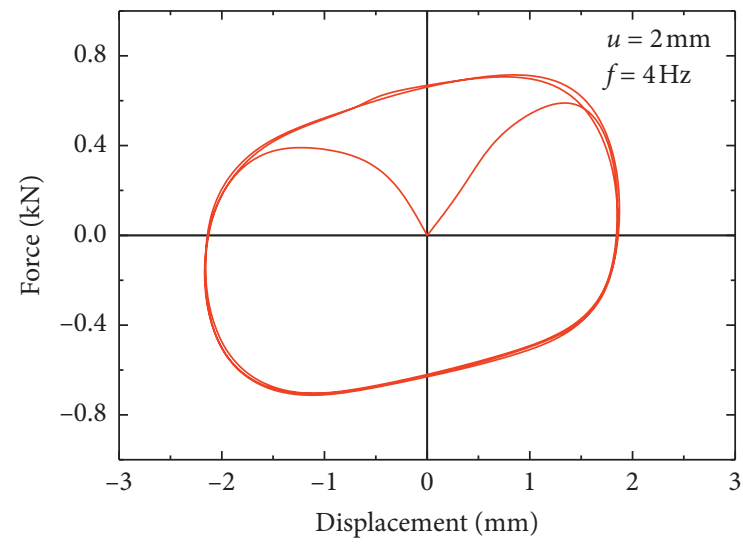

(b)

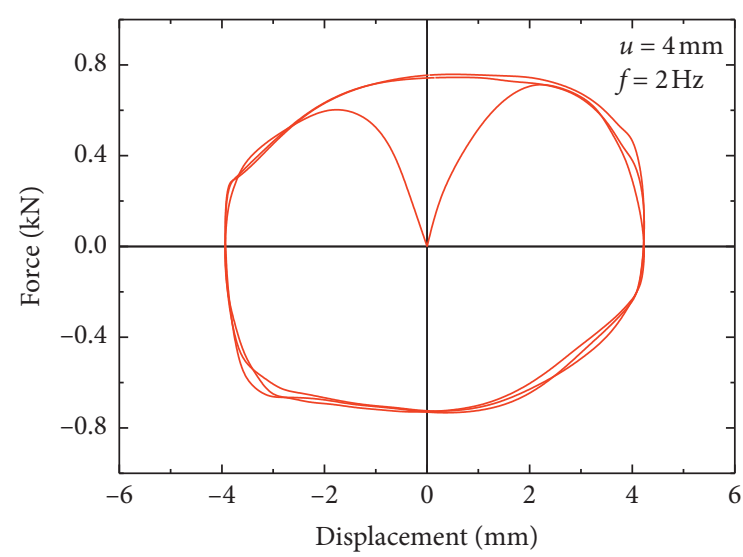

(d)

Figure 5: Hysteresis loops for the damper under different amplitude and frequency conditions. (a) $2 \mathrm{~mm}-3 \mathrm{~Hz}$. (b) $2 \mathrm{~mm}-4 \mathrm{~Hz}$. (c) 4 mm$1 \mathrm{~Hz}$. (d) $4 \mathrm{~mm}-2 \mathrm{~Hz}$.

H-shaped steel of $\mathrm{HM} 200 \times 150 \times 6 \times 9$ was used for the column and beam, and a square steel tube of $50 \times 50 \times 10$ was used for the connection rod. The steel specification and size can be referred to Chinese Standard [19]. The thicknesses of the joint and stiffened plates were all $10 \mathrm{~mm}$. All the steel used was Q235 [19]. The ends of the beam were bolted to the columns, forming simple connections. Moreover, the scissor jack was connected to the frame by steel plates designed to undergo mainly rotation and to prevent inelastic action.

An electro-hydraulic servo actuator, manufactured by the company American MTS, was employed to exert sinusoidal displacement excitations of various frequencies and amplitudes at the beam-column connection, as shown in 


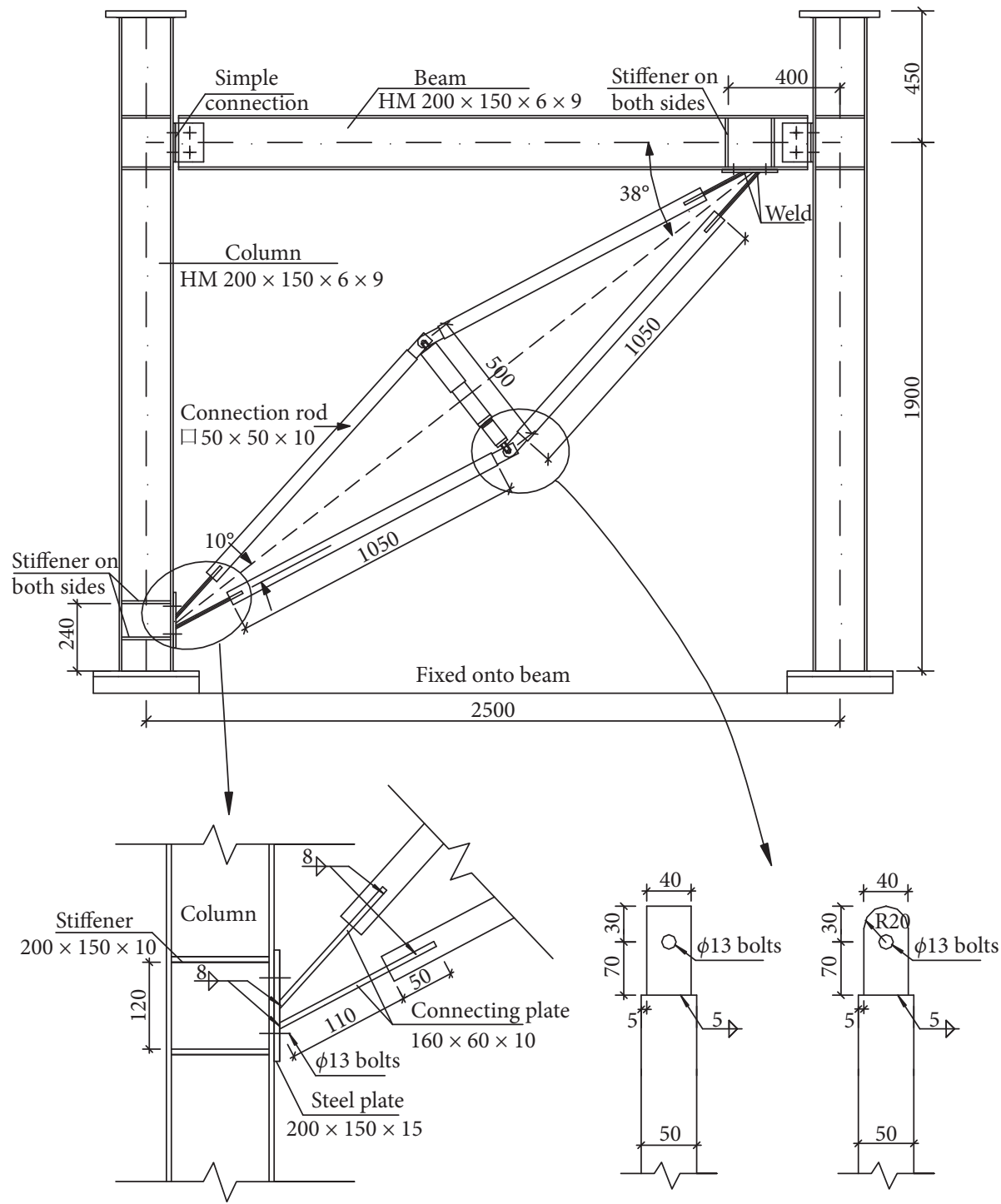

FIGURE 6: Details of the tested efficient scissor-jack-damper configuration.

Figure 7. The amplitudes were 2,4 , and $6 \mathrm{~mm}$, and the loading frequencies were $0.01,0.05,0.5,1,2,3$, and $4 \mathrm{~Hz}$. The frequencies 0.01 and $0.05 \mathrm{~Hz}$ were considered to represent quasistatic conditions, while the other frequencies represented dynamic conditions. The horizontal displacement at the joint, the relative displacement of the damper, the displacement of the foundation beam, the output force of the actuator, and the damper force were recorded during the experiment [20].

3.3. Test Result Analysis. The behavior of the efficient scissorjack-damper system is illustrated in Figures 8-10. These figures show, respectively, the relationships between the lateral force and the lateral displacement of the specimen, between the damper force and the damper displacement, and between the damper displacement and the specimen lateral displacement. Notably, the specimen lateral displacement is the displacement of the beam-column joint, and the lateral force is the applied force. A rightward drift (i.e., resulting in a decrease in the damper length) is taken as corresponding to a positive force acting on the specimen and to a negative damper force.

The curves in Figures 8-10 are all symmetrical as a result of the small loading displacements and of the absence of slipping in the bolt holes. The lateral force-lateral displacement loops shown in Figure 8 reveal the stiffness and damping characteristics of the tested model. Figure 8 shows that, for a given amplitude, the lateral force-lateral displacement curves become full with increasing loading frequency, which indicates that the fluid viscous damper dissipates more energy at higher frequencies. It is clearly demonstrated that the fluid viscous damper has almost no effect at $0.01 \mathrm{~Hz}$ loading frequency, and there is essentially no force acting on the damper. Thus, the frame effectively displays undamped behavior under quasi-static conditions at $0.01 \mathrm{~Hz}$ and $0.05 \mathrm{~Hz}$. 


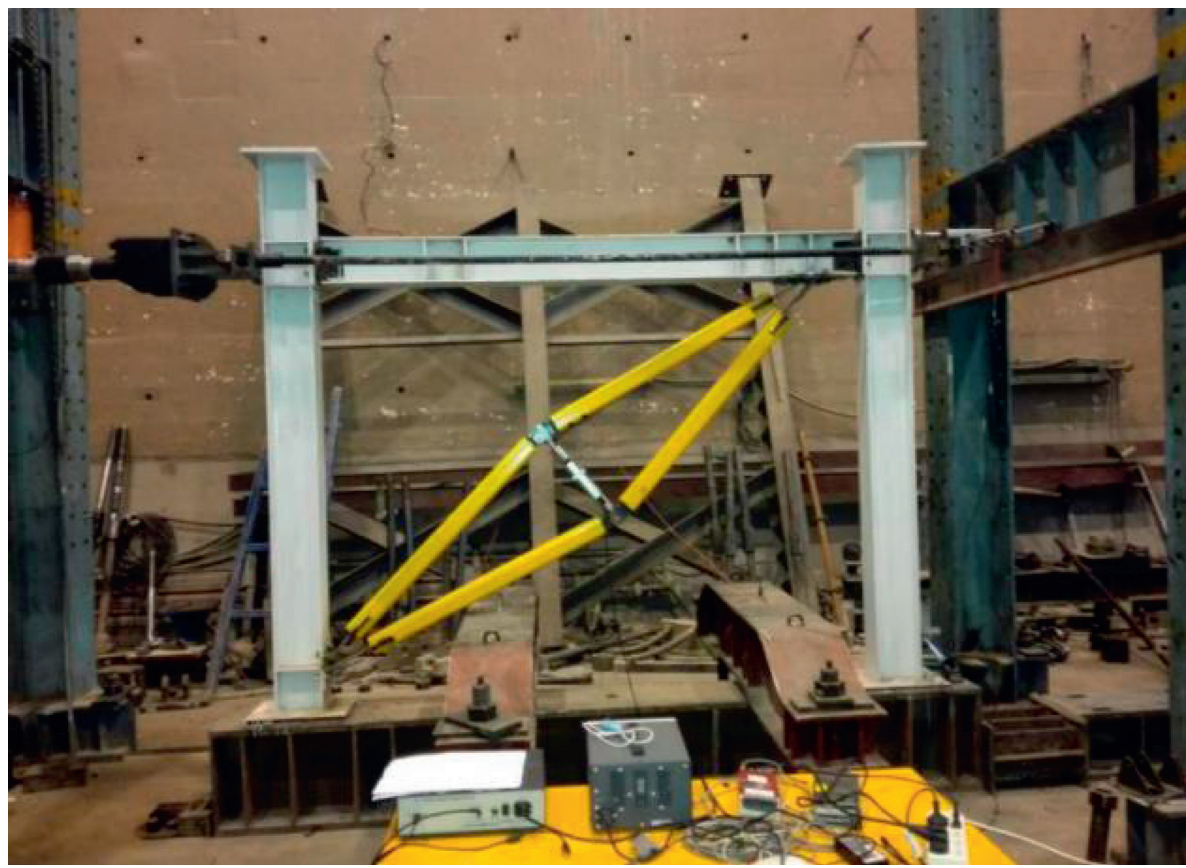

(a)

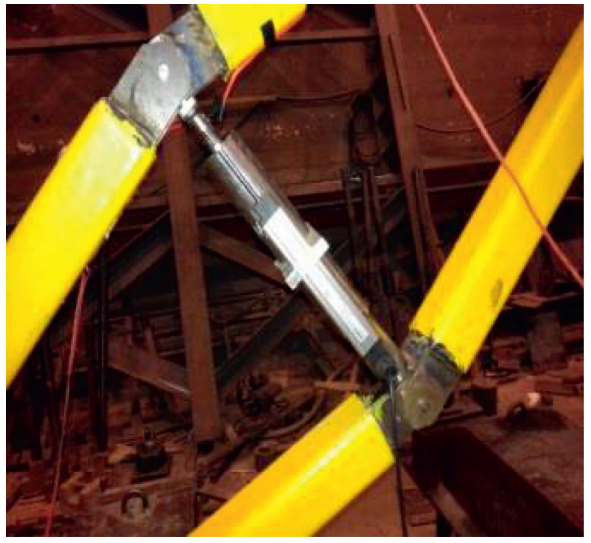

(b)

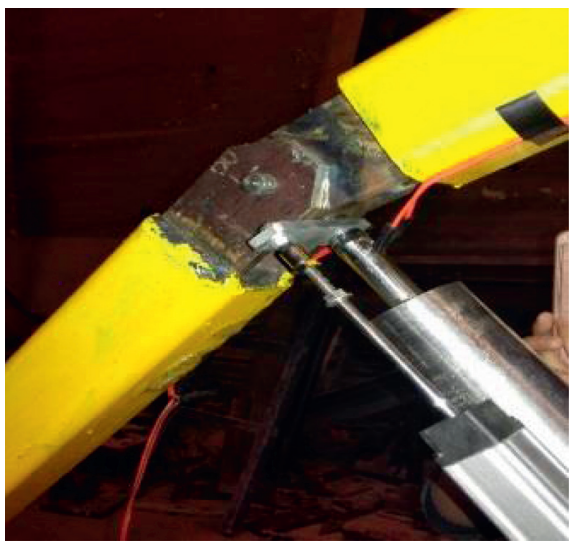

(c)

Figure 7: Test setup.

For the tested model $\left(\theta=10^{\circ}\right.$ and $\left.\psi=38^{\circ}\right)$, the theoretical prediction of the magnification factor is $f=\cos \psi / \tan \theta=4.469$. The damper displacement-lateral displacement hysteresis curves presented in Figure 10 display the effect of the underlying magnification factors. The measured displacement magnification factors were determined as the ratio of the damper peak displacement to the specimen peak lateral displacement, listed in Table 1. The magnification factor is maximized under the quasi-static condition $(0.01 \mathrm{~Hz})$, when the damper force is practically zero, and decreases with increasing frequency. It is concluded that the measurements show good agreement with the predictions of equation (5), especially at low loading frequencies. This verifies the accuracy of equation (5).

\section{Numerical Analysis}

To examine the damping performance of the efficient scissor-jack-damper configuration in the context of practical engineering, three numerical models were constructed and analyzed using SAP2000 [21]. These three models all involve seven-story and three-span plane steel-frame structures, as outlined in Figure 11. The structural system is a momentresisting frame, and the beam-to-column joint is rigid and of full strength. A linear elastic model was used for the steel frame. The steel frame is a plane model, and the panel zone was not modelled, but the dead load and live load acted on the panel were equivalent to the beam. The story heights are $3.6 \mathrm{~m}$, and the span is $6 \mathrm{~m}$. The column sections are HW $450 \times 450 \times 14 \times 22$ from the first to the third floor and 


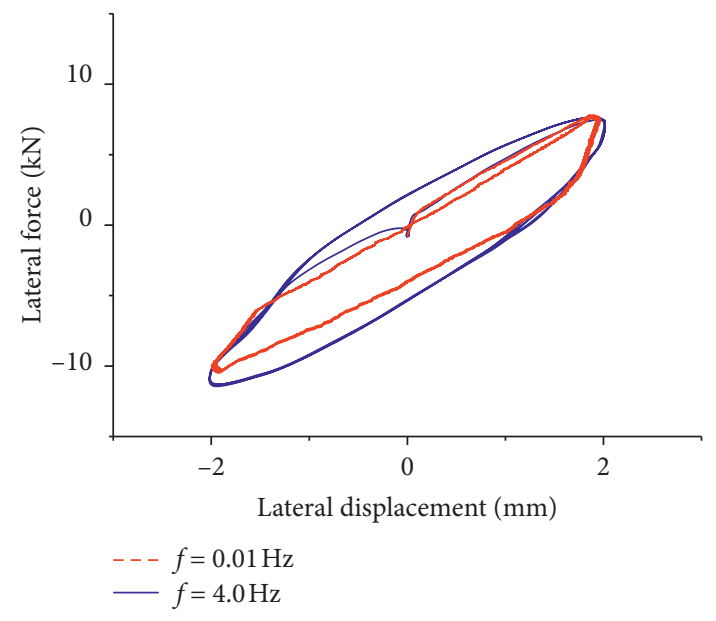

(a)

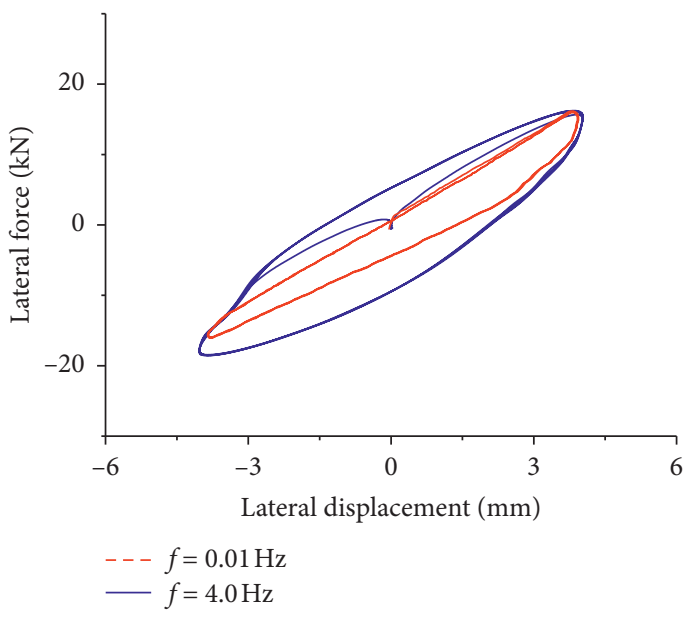

(b)

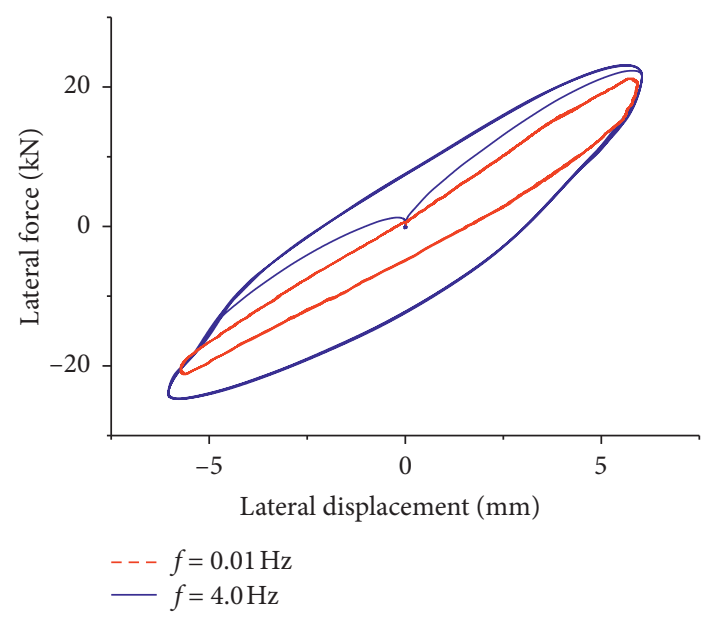

(c)

Figure 8: Load-displacement hysteresis curves for the specimen. (a) $2 \mathrm{~mm}$. (b) $4 \mathrm{~mm}$. (c) $6 \mathrm{~mm}$.

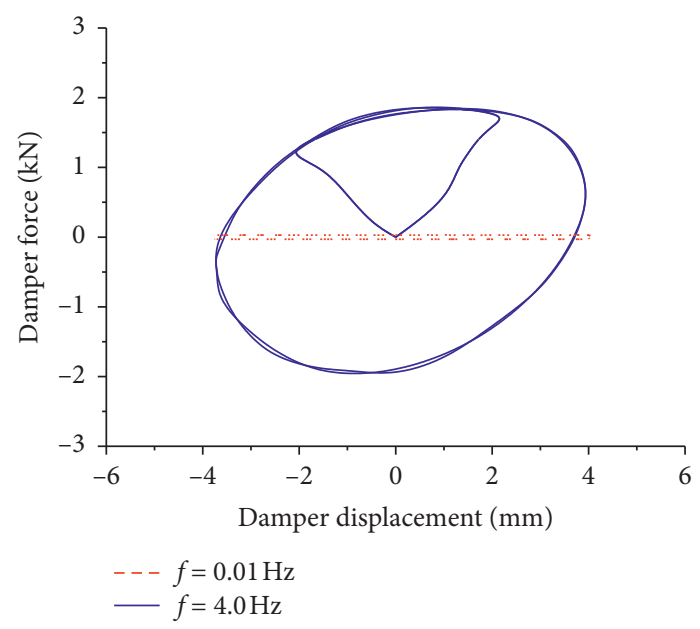

FIgURE 9: Hysteresis curves for the viscous damper.

HW $400 \times 400 \times 13 \times 21$ from the fourth to the seventh floor. The beam sections are HN400 $\times 200 \times 8 \times 13$ from the first to the third floor and $\mathrm{HN} 400 \times 200 \times 7 \times 11$ from the fourth to the seventh floor. The dead load on the frame beam is $25.2 \mathrm{kN} / \mathrm{m}$, and the live load is $12 \mathrm{kN} / \mathrm{m}$. Model $\mathrm{I}$ is an uncontrolled structure, model II is a frame structure with a 


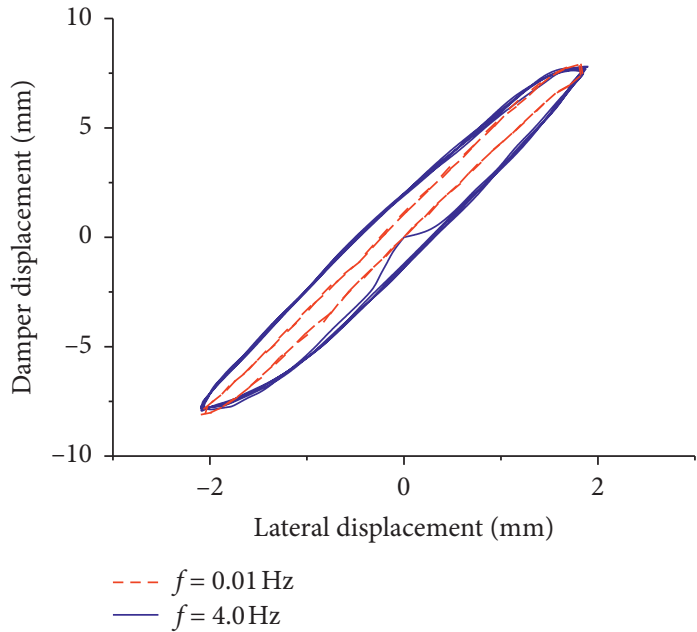

(a)

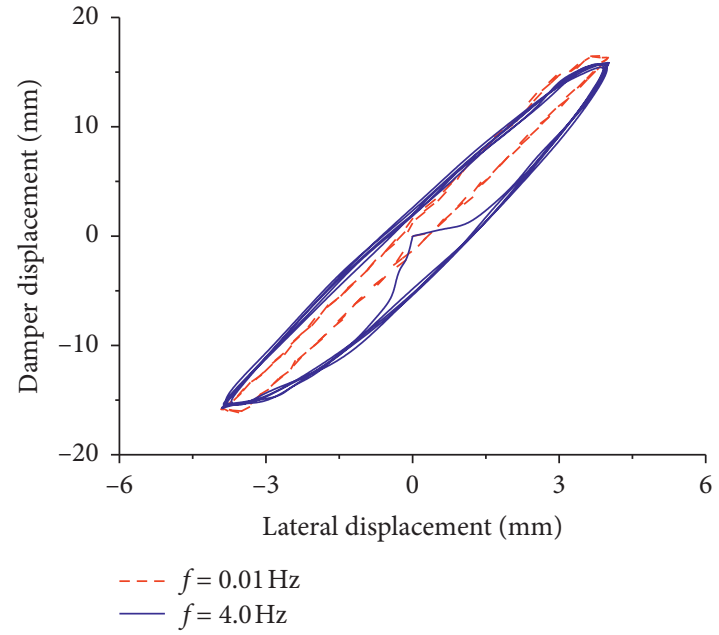

(b)

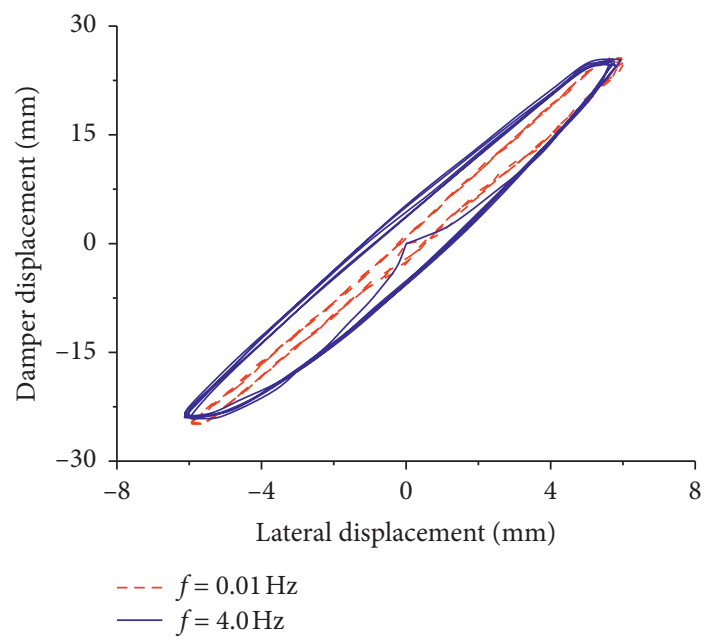

(c)

Figure 10: Damper displacement-lateral displacement hysteresis curves. (a) $2 \mathrm{~mm}$. (b) $4 \mathrm{~mm}$. (c) $6 \mathrm{~mm}$.

TABLE 1: Test results for the displacement magnification factors.

\begin{tabular}{lccr}
\hline Frequency $(\mathrm{Hz})$ & \multicolumn{2}{c}{ Displacement amplitude $(\mathrm{mm})$} \\
\hline 0.01 & 2 & 4.595 & 6 \\
0.05 & 4.560 & 4.548 & 4.612 \\
0.5 & 4.465 & 4.460 & 4.587 \\
1 & 4.453 & 4.440 & 4.562 \\
2 & 4.436 & 4.422 & 4.442 \\
3 & 4.415 & 4.401 & 4.428 \\
4 & 4.391 & 4.337 & 4.405 \\
\hline
\end{tabular}

diagonal-brace configuration, and model III is a frame structure with the proposed scissor-jack-damper configuration. The diagonal-brace configuration has $\theta=30.9^{\circ}$ and $f=\cos \theta=0.858$; the efficient scissor-jack-damper configuration has $\theta=12^{\circ}, \psi=33.7^{\circ}$, and $f=\cos \psi / \tan \theta=3.914$. The same viscous dampers with a damping coefficient of $C_{0}=1200 \mathrm{~N} \cdot \mathrm{s} / \mathrm{mm}$ were utilized in models II and III.
Modal analysis was first conducted, and then linear timehistory analysis of these three models was conducted under the El-Centro NS seismic wave. In accordance with the code requirements [22], the peak acceleration for the El-Centro NS seismic wave was adjusted to $70 \mathrm{~cm} / \mathrm{s}^{2}$, the frequentoccurred earthquake intensity level. The interstory shear force and drift are presented in Tables 2 and 3, respectively. 


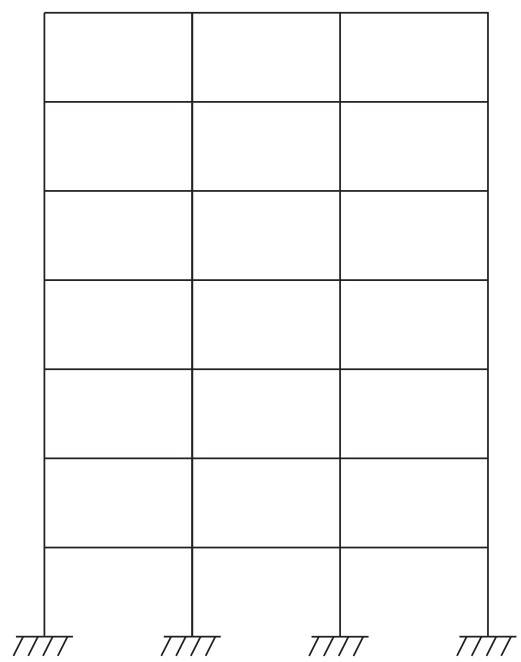

(a)
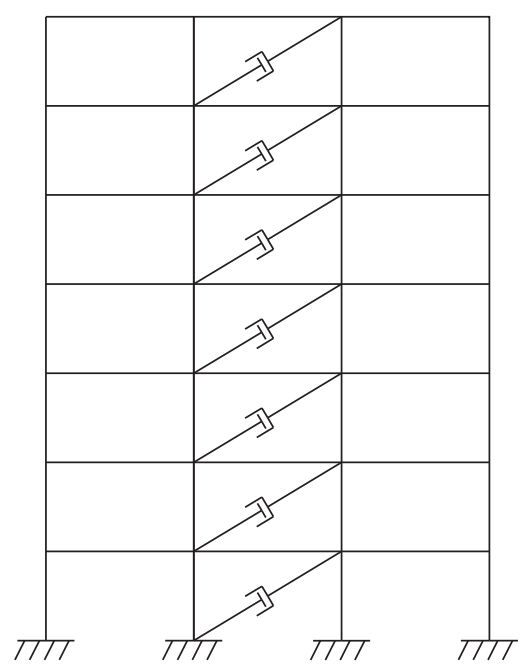

(b)

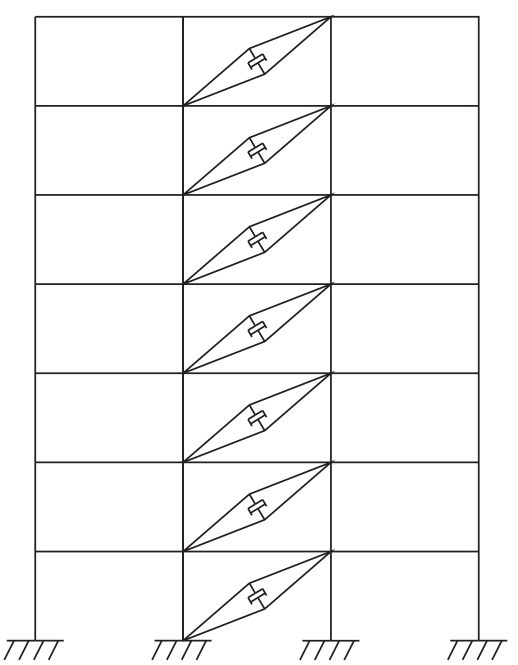

(c)

Figure 11: Numerical models. (a) Model I. (b) Model II. (c) Model III.

TABLE 2: Interstory shear force under the El-Centro NS seismic wave.

\begin{tabular}{lccccc}
\hline Floor & \multicolumn{2}{c}{ Model I } & \multicolumn{2}{c}{ Model II } & Model III \\
& Interstory shear force $(\mathrm{kN})$ & $\begin{array}{c}\text { Interstory shear } \\
\text { force }(\mathrm{kN})\end{array}$ & Seismic-reduction ratio & Interstory shear force $(\mathrm{kN})$ & Seismic-reduction ratio \\
\hline 7 & 67 & 49 & 26.9 & 20 & 70.1 \\
6 & 96 & 72 & 25.0 & 34 & 64.6 \\
5 & 109 & 86 & 21.1 & 41 & 62.4 \\
4 & 117 & 93 & 20.5 & 52 & 55.6 \\
3 & 132 & 106 & 19.7 & 62 & 60.6 \\
2 & 157 & 123 & 21.7 & 69 & 64.1 \\
1 & 192 & 146 & 24.0 & & 60.5 \\
\hline
\end{tabular}

TABLE 3: Interstory drift under the El-Centro NS seismic wave.

\begin{tabular}{lccccc}
\hline Floor & $\begin{array}{c}\text { Model I } \\
\text { Interstory drift }\end{array}$ & Interstory drift & $\begin{array}{c}\text { Model II } \\
\text { Seismic-reduction ratio }\end{array}$ & $\begin{array}{c}\text { Model III } \\
\text { Seismic-reduction ratio (\%) }\end{array}$ \\
\hline 7 & $1 / 957$ & $1 / 1247$ & 23.3 & $1 / 2647$ & 63.8 \\
6 & $1 / 787$ & $1 / 1002$ & 21.5 & $1 / 1946$ & 59.6 \\
5 & $1 / 752$ & $1 / 935$ & 19.6 & $1 / 1779$ & 57.7 \\
4 & $1 / 735$ & $1 / 893$ & 17.7 & $1 / 1593$ & 53.9 \\
3 & $1 / 748$ & $1 / 935$ & 20.0 & $1 / 1680$ & 55.5 \\
2 & $1 / 791$ & $1 / 971$ & 18.5 & $1 / 2233$ & 57.2 \\
1 & $1 / 910$ & $1 / 1149$ & 20.8 & 59.2 \\
\hline
\end{tabular}

The displacement of each floor and the displacement response of the top floor are plotted in Figure 12. The seismicreduction ratio, specified in Tables 2 and 3, is defined as the ratio of the difference between the seismic responses of the uncontrolled and controlled structures to the response of the uncontrolled structure. Tables 2 and 3 and Figure 12 suggest that the seismic response of the controlled structure is less than that of the uncontrolled structures. Especially for the model with the efficient scissor-jack-damper configuration, the seismic response is significantly reduced, with the seismic-reduction ratio reaching $55 \%$ to $65 \%$. Furthermore, it is noted that the efficient scissor-jack-damper configuration is more efficient than the diagonal-brace configuration.

Linear time-history analysis of these three models under the Taft seismic wave and the Lanzhou artificial seismic wave was also done. In these earthquake ground motion conditions, the efficient scissor-jack-damper configuration all showed good damping performance. Considering the purpose of the numerical analysis, only one steel-frame structure was employed, which would not affect the generality of analysis conclusions. 


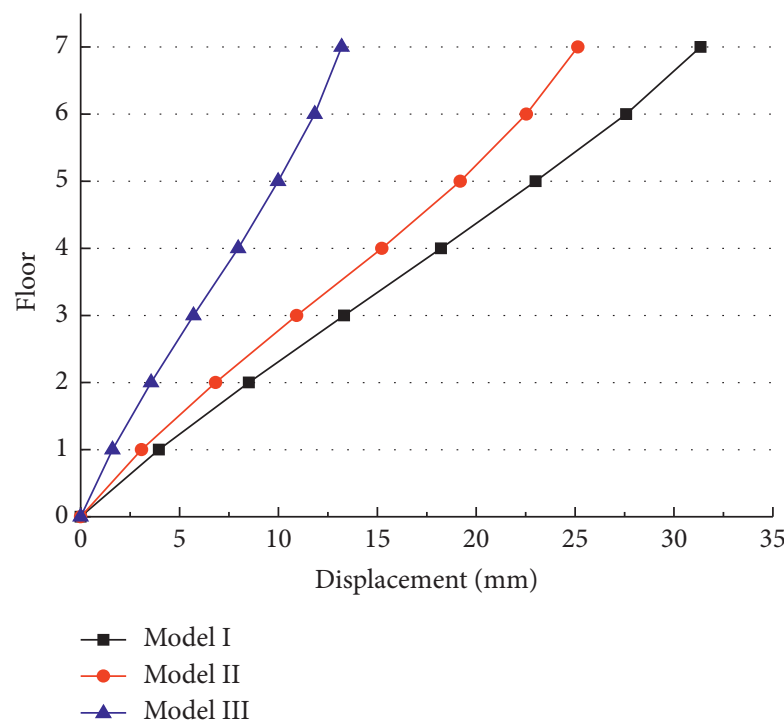

(a)

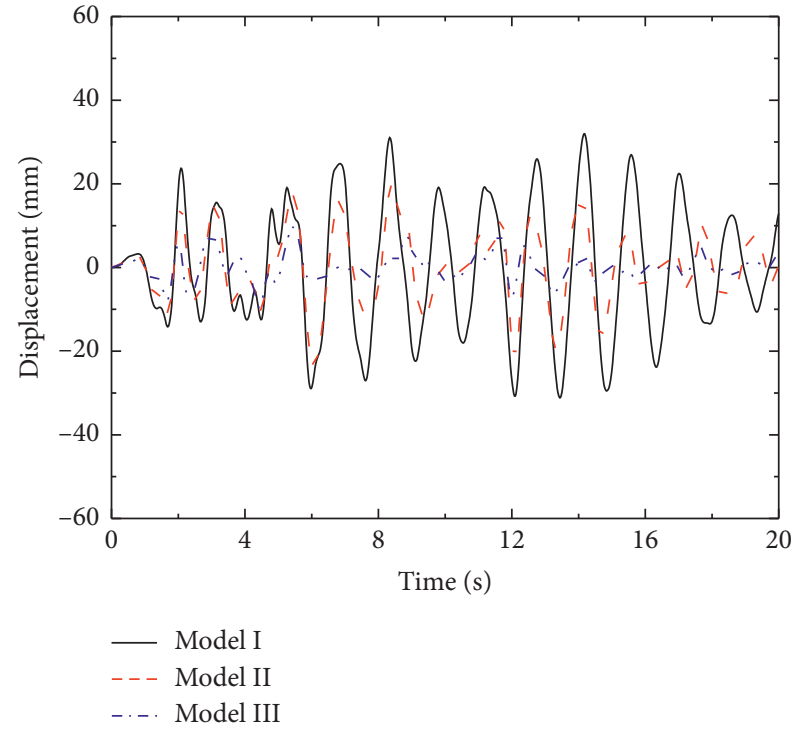

(b)

Figure 12: Displacement response under the El-Centro NS seismic wave. (a) Lateral displacement. (b) Top-floor displacement.

\section{Conclusions}

In conclusions, this paper presented a modified scissor-jackdamper configuration with a substantially improved efficiency. A theoretical analysis, an experimental investigation, and a numerical analysis on the configuration were conducted, supporting the following conclusions:

(1) The efficient scissor-jack-damper configuration increases the displacement magnification factor significantly, which is beneficial for the load transfer of earthquake action.

(2) The formula for the displacement magnification factor for the efficient scissor-jack-damper configuration was derived theoretically, and its accuracy was verified experimentally.

(3) Numerical models were linear, and beam-to-column joints were rigid and of full strength. Linear timehistory analysis results show that a structure with the efficient scissor-jack-damper configuration has a good energy-dissipation capacity and seismic-mitigation ability, thereby verifying the suitability of the efficient scissor-jack-damper configuration for practical engineering situations.

\section{Data Availability}

The data used to support the findings of this study are available from the corresponding author upon request.

\section{Conflicts of Interest}

The authors declare that they have no conflicts of interest.

\section{Acknowledgments}

The present work was funded by the project of the National Natural Science Foundation of China (51878552) and the Shaanxi Province Key Research and Development Program on Industry Innovation Chain (2018ZDCXL-SF-03-03-01).

\section{References}

[1] M. D. Symans, F. A. Charney, A. S. Whittaker et al., "Energy dissipation systems for seismic applications: current practice and recent developments," Journal of Structural Engineering, vol. 134, no. 1, pp. 3-21, 2008.

[2] X. He, Y. Yang, X. Xiao, and Y. Deng, "Research on fluid viscous damper parameters of cable-stayed bridge in northwest China," Shock and Vibration, vol. 2017, Article ID 4532325, 9 pages, 2017.

[3] M. C. Constantinou, T. T. Soong, and G. F. Dargush, Passive Energy Dissipation Systems for Structural Design and Retrofit, Multidisciplinary Center for Earthquake Engineering Research, Buffalo, NY, USA, Monograph No. 1, 1998.

[4] T. T. Soong and G. F. Dargush, Passive Energy Dissipation Systems in Structural Engineering, Wiley, Chichester, UK, 1997.

[5] C. Christopoulos and A. Filiatrault, Principles of Passive Supplemental Damping and Seismic Isolation, IUSS Press, Pavia, Italy, 2006.

[6] M. C. Constantinou, P. Tsopelas, W. Hammel, and A. N. Sigaher, "Toggle-brace-damper seismic energy dissipation systems," Journal of Structural Engineering, vol. 127, no. 2, pp. 105-112, 2001.

[7] J.-S. Hwang, Y.-N. Huang, and Y.-H. Hung, "Analytical and experimental study of toggle-brace-damper systems," Journal of Structural Engineering, vol. 131, no. 7, pp. 10351043, 2005. 
[8] A. N. Şigaher and M. C. Constantinou, "Scissor-jack-damper energy dissipation system," Earthquake Spectra, vol. 19, no. 1, pp. 133-158, 2003.

[9] S. Berton and J. E. Bolander, "Amplification system for supplemental damping devices in seismic applications," Journal of Structural Engineering, vol. 131, no. 6, pp. 79-83, 2005.

[10] J. S. B. Mosquera, J. L. Almazán, and N. F. Tapia, “Amplification system for concentrated and distributed energy dissipation devices," Earthquake Engineering \& Structural Dynamics, vol. 45, no. 6, pp. 935-956, 2016.

[11] M. Ferraioli, A. Lavino, and A. Mandara, "Behaviour factor of code-designed steel moment-resisting frames," International Journal of Steel Structures, vol. 14, no. 1, pp. 243-254, 2014.

[12] R. Landolfo, "Seismic design of steel structures: new trends of research and updates of Eurocode," Recent Advances in Earthquake Engineering in Europe, vol. 46, pp. 413-438, 2018.

[13] Federal Emergency Management Agency (FEMA), NEHPR Recommended Seismic Provisions for New Building and Other Structures, Federal Emergency Management Agency (FEMA), Washington, DC, USA, 2015.

[14] H. C. Huang, "Efficiency of the motion amplification device with viscous dampers and its application in high-rise buildings," Earthquake Engineering and Engineering Vibration, vol. 8, no. 4, pp. 521-536, 2009.

[15] J.-S. Hwang, Y.-N. Huang, S.-L. Yi, and S.-Y. Ho, "Design formulations for supplemental viscous dampers to building structures," Journal of Structural Engineering, vol. 134, no. 1, pp. 22-31, 2008.

[16] M. C. Constantinou and A. N. Şigaher, "Energy dissipation system configurations for improved performance," in Proceedings of the 2000 Structures Congress \& Exposition, ASCE, Philadelphia, PA, USA, May 2000.

[17] R. D. Hanson and T. T. Soong, Seismic Design with Supplemental Energy Dissipation Devices, Earthquake Engineering Research Institute, Oakland, CA, USA, Monograph No. 8, 2001.

[18] D. P. Taylor and M. C. Constantinou, "Testing procedures for high output fluid viscous dampers used in building and bridge structures to dissipate seismic energy," Shock and Vibration, vol. 2, no. 5, pp. 373-381, 1995.

[19] China Architecture and Building Press, Standard for Design of Steel Structures (GB50017-2017), China Architecture and Building Press, Beijing, China, 2017.

[20] L. Zhu, J. Dai, and G. Bai, "Sensor placement optimization of vibration test on medium-speed mill," Shock and Vibration, vol. 2015, Article ID 690196, 9 pages, 2015.

[21] Computers and Structures, Inc., SAP2000 [Computer and Software], Computers and Structures, Inc., Berkeley, CA, USA, 2000.

[22] China Architecture and Building Press, Code for Seismic Design of Buildings (GB50011-2011), China Architecture and Building Press, Beijing, China, 2016. 